\title{
«ГЕОМЕТРИЧЕСКИЙ» ВЗГЛЯД НА ПРИРОДУ СТЕПЕННЫХ ЗАВИСИМОСТЕЙ В РАЗВИТИИ ГЕОЛОГИЧЕСКИХ (И ПРОЧИХ ПРИРОДНЫХ) ПРОЦЕССОВ
}

\author{
Ильченко В.Л.
}

Геологический институт КНЦ РАН, Апатиты, vadim@geoksc.apatity.ru

\begin{abstract}
Аннотация
Проведённый геометрический анализ уже известных эмпирических нелинейных закономерностей развития внешней оболочки Земли завершился вполне успешно. Получены новые результаты, требующие дополнительного исследования. Подтверждена родственность формул $M_{n}=M_{0} \cdot 2^{-n}$ (механизм тектонического расслоения внешней земной оболочки) и $M_{0}=M_{n} \cdot \sqrt{2}^{-n}$ (механизм развития систем концентрических нарушений вокруг контрастных геологических объектов (в том числе породных массивов и глубоких горных выработок). Показана возможность реального существования прямой связи между «квантовыми» и «глобальными» волновыми системами.
\end{abstract}

\section{Summary}

The geometrical analysis of already known empirical nonlinear patterns of the outer Earth shell development was completed quite successfully. New results were obtained that require additional study. The affinity of the formulas was confirmed $M_{n}=M_{\Delta_{n}} \cdot 2^{-n}$ for the mechanism of tectonic layering of the outer Earth shell and $M_{0}=M_{n} \cdot \sqrt{2}^{-n}$ the mechanism for developing of concentric disturbances around contrast geological objects (including rock massifs and deep mine workings.) The possibility of the real direct connection between "quantum" and "global" wave systems was shown.

\section{Введение}

Как известно, все фундаментальные физические законы были выведены эмпирически и, часто, путём весьма продолжительных наблюдений за природой. При этом фундаментальная наука до сих пор «не вполне доверяет» (или даже игнорирует) некоторым эмпирическим законам, описываемым степенными функциями (в сейсмологии - закон Гутенберга-Рихтера, Омори и др., в биостратиграфии - гистограмма событий вымирания видов или «кривая смерти» Раупа, в геохронологии и геохимии - явление полураспада тяжёлых элементов и др.), на которых построена теория самоорганизованной критичности П. Бака [1]. Видимо, фундаментальная наука «не любит» теорию самоорганизованной критичности (CK) потому, что эти её законы эмерджентны, но не выводятся аналитически и, хотя теория прекрасно работает, полученные с её помощью решения обычно носят вероятностный характер.

Внешняя земная оболочка не является сплошной средой, так как имеет глыбово-блочное строение и пронизана системами трещин. Трещины (разломы) служат путями для рудных флюидов и создают проблемы недропользователям [17]. Трещиноватость характеризуется иерархичностью, фрактальным строением и описывается известными степенными законами (ряды, ге- 
ометрические прогрессии), но сейсмотектонические события (и их следствия) пока остаются непредсказуемыми и их рассматривают как «детерминированный хаос» [5].

На самом деле механизмы разрушения пород земной коры (и землетрясения [12]) имеют изначально волновую природу; верней, такую природу имеет механизм подготовки горных пород к разрушению. Кратко покажем это на двух примерах.

1) Механизм тектонического расслоения породного пространства внутри колебательной системы: $M_{n}=M_{0} \cdot 2^{-n}, M_{n}$ - мощность элемента (моды) расслоения, $n$ - номер моды $\left(0,1,2 \ldots\right.$, все целые числа), $M_{0}$ - мощность колебательной системы. Размер $M_{0}$ можно получить и «обратным» пересчётом из длины «конечной моды» $M_{n}: M_{0}=M_{n} \cdot 2^{n}$. Этот механизм впервые был предложен для построения модели тектонического расслоения земной коры Печенгского блока и как колебательной системы и, затем, доказан на разрезе Кольской сверхглубокой скважины (СГ-3) [7] и на многих других скважинах (пройденных в осадочных фанерозойских толщах, в т.ч. на шельфе Баренцева моря $[8,9])$.

2) Развитие концентрической системы тектонических нарушений вокруг геологического объекта (породного тела) с контрастными, относительно вмещающей среды, свойствами (сюда - как весьма контрастные объекты - относятся глубокие горные выработки) и которое регулярно превращает-

ся в источник колебаний, происходит по закону $M_{n}=M_{0} \cdot \sqrt{2}^{n} ; M_{n}-n$-й радиус области тектонических нарушений, $n$ - её номер $(0,1,2 \ldots$, все целые числа), $M_{0}$ - мощность исходной (№0) колебательной системы. Исходный размер (длину моды) $M_{0}$, также как и в механизме тектонического расслоения [7], легко получить посредством «обратного» пересчёта: $M_{0}=M_{n} \cdot \sqrt{2}^{-n}[10$ и полезные ссылки там].

Сходство (и, по-видимому, близкое «родство») формул

$$
\text { 1) } M_{n}=M_{0} \cdot 2^{-\mathrm{n}} \text { и 2) } M_{0}=M_{\mathrm{n}} \cdot \sqrt{ } 2^{-\mathrm{n}}
$$

предполагает общий физический принцип для обеих ситуаций (в их основе одно ито жеявление), разница лишь в том, что припереходе «изнутри-наружу» в точке $M_{0}$, динамика описываемого процесса меняется. Изменения вытекают из ситуаций: в случае (1) основная часть приливнойэнергии остаётся «внутри» колебательной системы, а случай (2) описывает работу «остаточной» энергии, что уходит из колебательной системы во внешнюю среду. В итоге получается два числовых ряда (геометрические прогрессии), начинающихся в точке $M_{0}$, причём развитие первого происходит с убыванием длин мод по мере роста их количества - за счёт их пошагового деления пополам, а второго - с пошаговым возрастанием длин мод.

Рабочая версия процессов подготовки пород к тектоническому расслоению состояла в следующем: колебание в породах внешней земной оболоч- 
ки вызывается - на «квантовом» уровне - наподобие эффекта Мёсбауэра [18] - силой лунной гравитации (солнечно-лунный прилив). Очень скоро, после ухода источника этих возмущений (Луны) из точки «зенита» приливное колебание преобразуется в стоячую волну, которая вынуждена перейти в режим затухания, что ведёт к развитию в колеблющейся среде системы из множества узлов стоячей волны - точечных концентраторов избыточно высоких напряжений (поскольку сюда отжимается часть напряжений из зон колеблющихся пучностей стоячей волны), что и обусловливает всё последующее расслоение [7]. До настоящего времени нет более строгого физического описания этого явления, хотя сам механизм работает: он позволяет вычислять пространственное положение (вероятностную глубину) границ тектонического расслоения с достаточно высокой точностью (вероятность обусловлена пространственными вариациями физических - в том числе прочностных - свойств горных пород внешней земной оболочки).

В одной из последних работ на эту тему [11] приведены как бы вполне убедительные доводы в пользу постулата об эквивалентности гравитирующих масс (принципа ЭГМ), предполагающего, что масса источника гравитационных возмущений на Земле (Луны) равна массе области этого возмущения (в составе пары твёрдых приливных волн-антиподов). При этом остаётся без строгого доказательства механизм тектонического расслоения, основанный на физических условиях в режиме затухания стоячих волн (волновой контроль) [7].

Дальнейшие рассуждения нацелены на то, чтобы как-то приблизиться к более строгому, по понятиям фундаментальной науки, доказательству правомерности применения механизма тектонического расслоения на практике («сверхзадача» исследований: придание механизму тектонического расслоения и принципу ЭГМ статуса «Закон Природы»).

\section{Геометрия}

Идея о привлечении законов геометрии к доказательству волновой природы механизмов тектонического расслоения и развития систем концентрической зональности тектонических нарушений вокруг контрастных геологических объектов возникла несколько лет назад - во время работы над статьёй о развитии посттехногенных нарушений в породных массивах [13]. Но в той статье был рассмотрен наиболее простой случай: развитие системы тектонических нарушений вокруг выработки квадратного сечения, хотя эти сечения часто имеют (по разным причинам) довольно-таки произвольную форму, причём закономерность развития системы тектонических нару-

шений $R_{n}=r_{0} \cdot \sqrt{2}^{n}\left(R_{n}\right.$ - радиус $n$-й тектонической зоны, $r_{0}-$ «радиус» контура) эквивалентна известному геометрическому соотношению $R / r=\sqrt{2}$ $(R$ - радиус окружности, описанной вокруг квадрата, $r$ - радиус вписанной в этот квадрат окружности [3]) и выполняется для глубоких горных выработок почти повсеместно. За прошедшие 30 лет механизм формирования этого яв- 
ления так и не выяснен «большой наукой» $[14,15]$. Ниже приводится попытка пояснить развитие тектонической зональности «геометрическим» путём.

Развитие зон тектонических нарушений вокруг выработки начинается уже на её контуре. Стенки квадратного контура $\mathrm{ABCD}$ (рис. 1, слева), регулярно превращаются в колебательные системы лунным приливом, либо вследствие какого-то техногенного воздействия (взрывами, вибрацией от работы тяжёлых механизмов поблизости и т.п.). Эти стенки ограничены углами в пространстве и, если проводить аналогию с натянутой струной (как в [7]), эти углы играют ту же самую роль, что и её закреплённые концы: это узловые точки стоячей волны. Конечно же, стенки горной выработки не «играют» столь интенсивно, как на рисунке (стрелками изображён колебательный процесс), но под волновой контроль попадает всё породное вещество между хордой окружности (AB, например) описанной вокруг контура выработки и касательной $\left(\mathrm{A}_{1} \mathrm{~B}_{1}\right)$ к этой окружности, которая параллельна хорде (AB). То же самое происходит по всему контуру. Как и при развитии границ тектонического расслоения (по формуле $(1))$, касательная $\left(\mathrm{A}_{1} \mathrm{~B}_{1}\right)$ постепенно превращается в линейный концентратор избыточных упругих напряжений, что предполагает появление здесь зоны нарушений. Это первый шаг в процессе развития тектонической зональности - появление 1-й зоны

$\mathbf{B}_{2}$

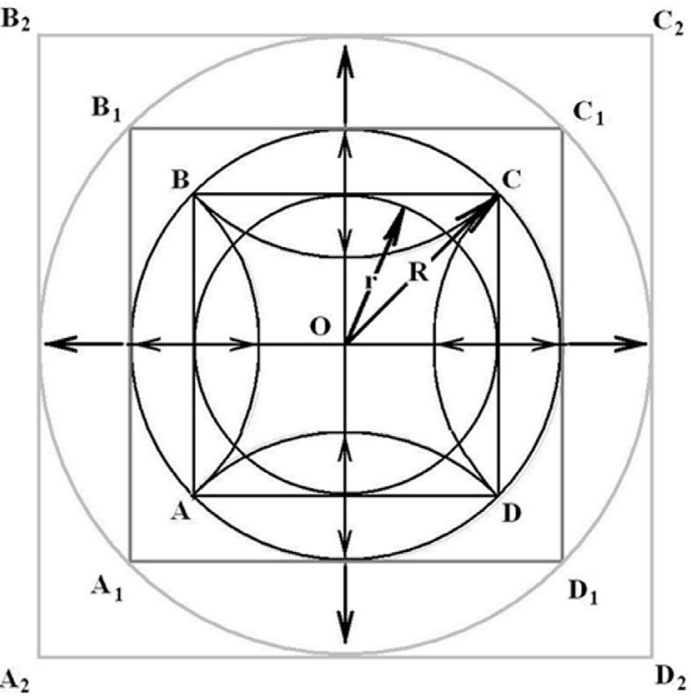

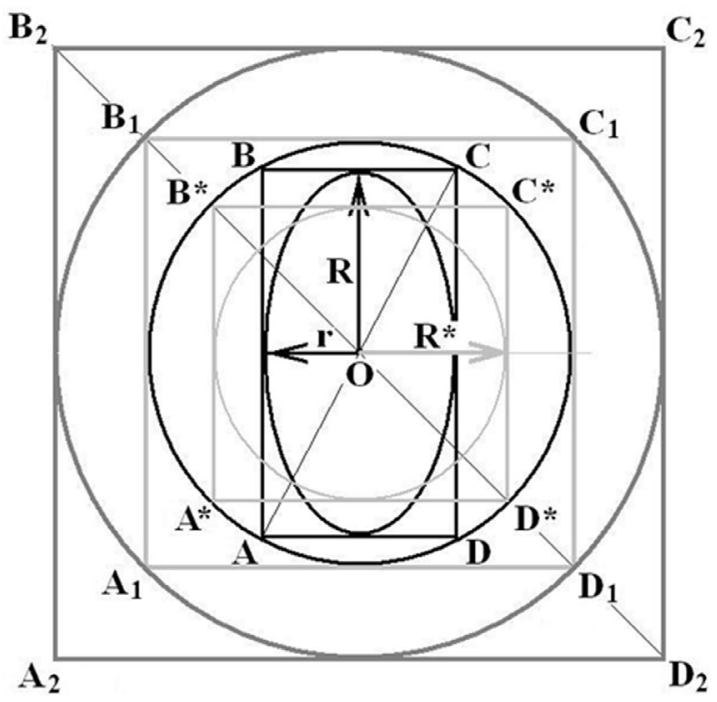

Рис. 1. Схемы развития системы зон тектонических нарушений вокруг контуров глубоких горных выработок: слева - квадратного, справа - прямоугольного (неквадратного) сечения: $A B C D$ - исходный контур, с которого и начинается разрушение (мода №0), O - центр всех окружностей, $r$ - радиус окружности, вписанной в контур, $R$ - радиус окружности, описанной вокруг этого контура; $A_{1} B_{1} C_{1} D_{1}$ - первая зона нарушений, $A_{2} B_{2} C_{2} D_{2}$ - вторая зона нарушений. Пары стрелок в противоположные стороны от границ контура $A B C D$ означают колебательный проиесс, остальные указывают направление развития зон тектонических нарушений. Для схемы справа всё так, как и для левой, за исключением: $r$-малый радиус эллипса вписанного в неквадратный контур, $R$ - большой радиус того же эл-

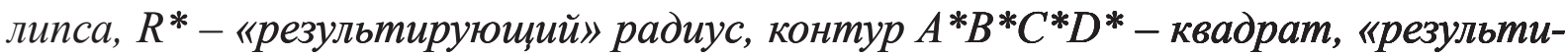
рующйй» по радиусу. 
нарушений, которая на рисунке обозначена контуром $\mathrm{A}_{1} \mathrm{~B}_{1} \mathrm{C}_{1} \mathrm{D}_{1}$. Теперь этот контур превращается в колебательную систему и всё повторяется - с развитием новой системы тектонических нарушений (по формуле (2)).

Горные выработки с контуром идеальной квадратной формы встречаются не часто и, по-видимому, их в природе не существует. Скорей всего, наиболее распространены контуры выработок прямоугольного (но, не квадратного) сечения (контур $\mathrm{ABCD}$, рис. 1, справа). При этом известно, что любой брошенный в воду предмет, невзирая на его форму, создаёт вокруг себя именно круглую (кольцевую) волну. И вот тут возникает проблема, препятствующая применению соотношения $R / r=\sqrt{2}(R-$ радиус описанной вокруг квадрата окружности, $r$ - радиус вписанной [3]), поскольку в прямоугольный (неквадратный) контур можно вписать лишь эллипс (не круг), который имеет два радиуса: малый $r$ и большой $R$. Чтобы получить квадратный контур (условие для формулы $R / r=\sqrt{2}$ ), «превратим» этот прямоугольник в квадрат, просто манипулируя радиусами эллипса и получим результирующий радиус $R^{*}=(R+r) / 2$. Физическое оправдание этой операции состоит в том, что мы имеем дело с нелинейным волновым процессом, где каждая сторона контура выступает как источник одиночных волн - солитонов, превращающих далее приконтурное породное пространство в регулярную колебательную систему, периодически работающую в режиме затухания, то есть - под волновым контролем [7]. Эллипс же трансформируется в круг опять же благодаря солитонной природе отражённых от контура волн: чем больше длина стороны контура, тем больше солитон (длина волны - $\lambda$ ) и тем быстрей он движется [16]. Длина волны $\lambda$ равна длине стороны контура; для описанных и вписанных в окружность четырёхугольников есть строгие математические правила и соотношения [3], что должно распространяться и на свойства солитонов, которые генерируются отражающими границами (сторонами контура). По-видимому, трансформация эллипса в круг обусловлена, в описы-
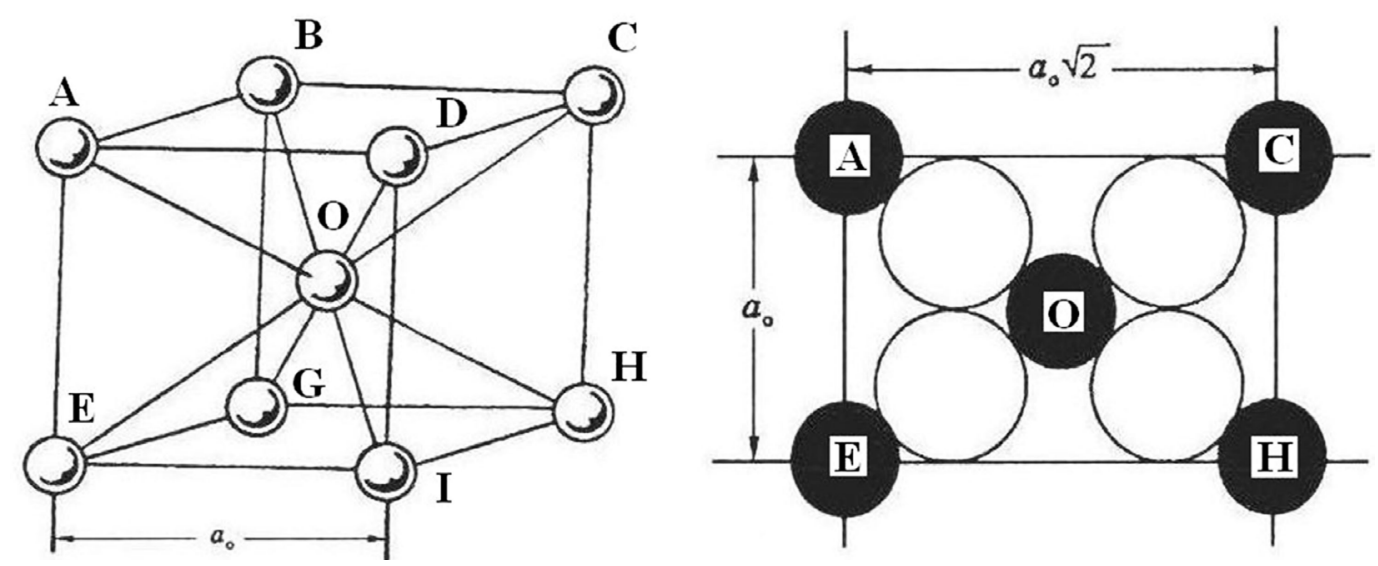

Рис. 2. Из [6] с дополнением. Слева: кристаллическая структура $\alpha-F e\left(O_{h}{ }^{9}-1 m 3 m\right.$, $Z=2)$. Справа: островно-электронная модель структуры $\alpha-F e(V I I I)$ в плоскости (110): чёрные круги - остовы $\mathrm{Fe}^{8+}$ радиусом 0.45 A; пустые круги - двухзарядные связывающие электронные облака $\left(2 e^{-}\right)$радиусом 0.62 А-разрез кубика $\alpha$-железа по диагональной плоскости АСНЕ. 
ваемой ситуации чисто солитонными условиями: внешний энергетический источник создаёт одно возмущение, которое выглядит разбитым на 4 части, но за пределами источника эти части вновь сливаются в единое кольцо. Отсюда также следует, что горная выработка с контуром даже «неправильной» (непрямоугольной) четырёхугольной формы должна будет создавать тот же самый эффект, что и выработка с квадратным контуром.

Теперь, когда ситуация с развитием тектонической зональности слегка прояснилась (но пока только в «планиметрии»), испытаем приобретённые знания на 3-мерном пространстве. В качестве примера рассмотрим кристаллическую структуру $\alpha$-железа (рис. 2) из [6], чья элементарная ячейка представляется как объёмно-центрированный куб (ОЦК).

По аналогии с выработкой квадратного сечения, чей превращённый в колебательную систему контур генерировал систему стоячих волн, под и под чьим влиянием развивалась система концентрических зон тектонических нарушений в породном пространстве вокруг выработки, можно предположить, что то же самое, но в трёхмерном варианте, происходит или должно происходить вокруг колебательной системы кубической формы: вокруг кубика будет развиваться тектоническая зональность в форме системы концентрических сфер. Хотя экспериментальная проверка пока не представляется возможной, есть вполне приличный доказательный эмпирический материал: системы кольцевых нарушений вокруг Хибин [2] и тектоническая зональность вокруг глубоких горных выработок [14, 15 и др.]. Рисунок 2 (справа) позволяет сделать ещё один весьма полезный вывод, подкрепляющий гипотезу о физической сути вещества, которое выступает в качестве «наполнителя» колебательной системы, возбуждаемой извне (лунной гравитацией или неважно чем). В [11] - это электроны с внешней электронной оболочки ато-

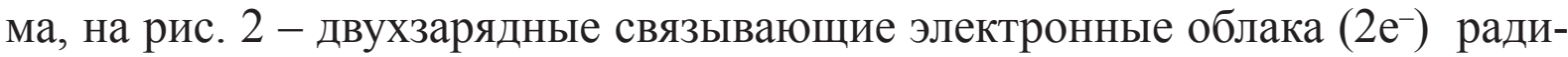
усом $0.62 \AA$. Этот радиус электронного облака, помноженный на $\sqrt{2}$, даёт предполагаемую область возмущения с радиусом $\mathrm{r} \approx 0.877 \AA$, что на 7 порядков больше вычисленной средней гравитационной (лунно-приливной) деформации растяжения электронного облака атома в составе внешней земной оболочки $\left(10^{-7}\right)[11]$ и на 8 порядков $\left(10^{-8}\right)$ больше амплитуды зарегистрированной гравитационной волны [4]. По-видимому, «погрешность» в 7-8 порядков вызвана неучтённым (в расчётах [11]) влиянием силы ядерного притяжения в структуре $\alpha-\mathrm{Fe}$.

\section{Заключение}

Проведённый в этой работе «геометрический» анализ ранее выявленных эмпирических нелинейных закономерностей развития внешней оболочки Земли оказался вполне успешным и привёл к получению новых результатов, которые требуют дополнительного исследования. Подтверждена родственность формул: $M_{n}=M_{0} \cdot 2^{-n}$ (механизм тектонического расслоения внешней земной оболочки) и $M_{0}=M_{n} \cdot \sqrt{2}^{-n}$ (механизм развития систе- 
мы концентрических нарушений вокруг контрастных геологических объектов, в том числе породных массивов и глубоких горных выработок). Показана возможность реального существования прямой связи между «квантовыми» и «глобальными» колебательными системами.

Работа выполнена в рамках Госзадания ГИ КНЦ РАН по теме НИР № 0231-2015-0006.

\section{Список литературы}

1. Бак П. Как работает природа: Теория самоорганизованной критичности. М.: УРСС Книжный дом «ЛИБРОКОМ». 2013. 276 с.

2. Беляев К.Д., Увадьев Л.И., Шульга Т.Ф. Закономерности размещения массивов центрального типа Кольского полуострова // ДАН. 1976. Т. 226. №1. С.163-165.

3. Бронштейн И.Н., Семендяев К.А. Справочник по математике для инженеров и учащихся вузов. М.: Наука. 1986. 544 с.

4. Десять крупнейших событий 2017 года // Наука и жизнь. 2018. №1. С.8. 5. Захаров В.С. Самоподобие структур и процессов в литосфере по результатам фрактального и данамического анализа. Автореф. дисс. д. г.-м. н. М.: Геол. ф-т МГУ. 2014. 35 с.

6. Зуев В.В. Конституция, свойства минералов и строение Земли (энергетические аспекты). СПб.: Наука. 2005. 402 с.

7. Ильченко В.Л. Моделирование тектонического расслоения земной коры как колебательной системы, возбуждаемой лунным приливом (на примере земной коры Печенгского блока, Балтийский щит) / Физико-химические и петрофизические исследования в науках о Земле. Мат. 13 международной конф. М. 2012. С.105-108.

8. Ильченко В.Л. Космические факторы (влияние Луны и Солнца) в геодинамике и возможность их применения в нефтегазовой отрасли (для некоторых видов прогноза) / Новые идеи в геологии нефти и газа - 2015. Материалы междун. науч.-практ. конф. на CD. Электронное издание. Изд.: МГУ. 2015. С.33-36.

9. Ильченко В.Л. Моделирование тектонического расслоения пород земной коры по каротажным данным (на примере Кольской сверхглубокой скважины и ряда скважин на шельфе Баренцева моря // «Современный этап геологического изучения Арктики и континентального шельфа России - проблемы и перспективы освоения минеральных ресурсов». Междун. науч.-практ. конф. к 45-летию ОАО «МАГЭ» 22-23 ноября 2017 года, Мурманск. На электронном носителе.

10. Ильченко В.Л. Волновая природа систем тектонических нарушений вокруг горных выработок и их аналогов (концентрических кольцевых разломов) на земной поверхности // Мат. Всерос. Конф. в ИГД СО РАН, «Геодинамика и напряженное состояние недр Земли», 2-6 октября 2017 г. - Новосибирск. 2017. // Сб. Фундаментальные и прикладные вопросы горных наук. T. 4. № 2. C. 47-52. 
11. Ильченко В.Л. Квантование лунной гравитации (энергии приливной волны) в земной оболочке и «квантовая» основа силы упругости // Вестник КНЦ РАН. 2017. № 1 Вып. 9. С. 34-42.

12. Ильченко В.Л., Кобринович Ю.О. Приливные волны и прогноз землетрясений // Росс. геофиз. журнал. 2014. № 53-54. С. 99-105.

13. Ильченко В.Л., Медведева С.Г. О посттехногенных нарушениях в массиве горных пород // Геоэкология. Инженерная геология. Гидрогеология. Геокриология. 2013. № 5. С. 454-458.

14. Кви Ч., Ли К., Бай Д., Чанышев А.И., Лиу П. Градиентная модель зональной дезинтеграции массива пород вокруг выработок глубокого залегания // ФТПРПИ. 2017. № 1. С. 25-37.

15. Опарин В.Н., Тапсиев А.П., Чанышев А.И. 1-я Китайско-Российская научная конференция «Нелинейные геомеханико-геодинамические процессы при отработке полезных ископаемых на больших глубинах». ФТПРПИ. № 3. 2011. С. 111-115.

16. Филиппов А.Т. Многоликий солитон. М.: Наука. 1990. 288 с. (Библиотечка «Квант». Вып. 48).

17. Шабаров А.Н., Цирель С.В. Обеспечение геодинамической безопасности при подземной разработке месторождений // Горный журнал. 2017. № 9. С. $65-70$.

18. Яворский Б.М., Детлаф А.А. Справочник по физике для инженеров и студентов вузов. М.: Наука. 1974. 944 с. 